\title{
Shear Band Formation in AISI 4340 Steel Under Dynamic Impact Loads: Modeling and Experiment
}

\author{
Daniel Odoh ${ }^{1)}$, Gbadebo Owolabi ${ }^{1) \dagger}$, Akindele Odeshi ${ }^{2)}$ and Horace Whitworth ${ }^{1)}$ \\ 1) Department of Mechanical Engineering, Howard University, 2300 6th Street NW, Washington, DC, 20059, USA \\ 2) Department of Mechanical Engineering, University of Saskatchewan, 57 Campus Drive, Saskatoon, SK, S7N 5A9, \\ Canada \\ [Manuscript received 23 February 2013, in revised form 6 April 2013] \\ (C) The Chinese Society for Metals and Springer-Verlag Berlin Heidelberg
}

\begin{abstract}
In this study, the occurrence of the adiabatic shear bands in AISI 4340 steel under high velocity impact loading was investigated using finite element analysis and experimental tests. The cylindrical specimen subjected to the impact load was divided into different regions separated by nodes using finite element method in ABAQUS environment with boundary conditions specified. The material properties were assumed to be lower in the region where the probability of strain localization is high based on prior experimental results in order to initialize the formation of the adiabatic shear bands. The finite element model was used to determine the maximum flow stress, the strain hardening, the thermal softening, and the time to reach the critical strain for the formation of adiabatic shear bands. Experimental results show that deformed bands were formed at low strain rates and there was a minimum strain rate required for the formation of the transformed band in the alloy and the cracks were initiated and propagated along the transformed bands leading to fragmentation under the impact loading. The susceptibility of the adiabatic shear bands to cracking was markedly influenced by the strain-rates and the initial material microstructure. The simulation results obtained were compared with the experimental results obtained from the AISI 4340 steel under high strain-rate loading in compression using split impact Hopkinson bars. A good agreement between the experimental and simulation results was obtained.
\end{abstract}

KEY WORDS: Adiabatic shear bands; Finite element model; Strain hardening; Thermal softening; Johnson-Cook model; AISI 4340 steel

\section{Introduction}

The heat generated during the impact loading leads to thermal softening which occurs simultaneously with strain hardening. As the deformation process continues, strain eventually becomes localized along narrow bands due to intense localized adiabatic heating leading to loss of load carrying capability of the material. This kind of bands is referred to as the adiabatic shear bands. The severe plastic deformation and adiabatic heating occurring along adiabatic shear bands can lead to intense distortion, fragment of the lattice, or recrystallization of grains ${ }^{[1]}$. The occurrence of adiabatic shear bands have been reported

† Corresponding author. Tel: +1 202806 6594; E-mail address: gbadebo.owolabi@howard.edu (Gbadebo Owolabi)

DOI: $10.1007 / \mathrm{s} 40195-013-0103-2$ in the metallic materials subjected to high strainloading both in compression and in torsion ${ }^{[2]}$, resulting to the fragmentation and failure of components $^{[3-5]}$. This phenomenon has also been observed not only in metallic materials but also in ceramic materials ${ }^{[6,7]}$ and polymeric materials ${ }^{[7,8]}$ during dynamic shock loading.

The microstructural evolution leading to the formation of the cracks within an adiabatic shear band in AISI 4340 steel was introduced in Ref. [9]. The tensile stress generated inside the shear bands eventually become sufficiently high enough to produce the microcracks or voids that elongate and rotate to form elliptical shape with major axis along the shear band propagation path. These elliptical voids are finally connected to form cracks that propagate along the shear band leading to fracture. An adequate understanding of adiabatic shear band formation in mate- 


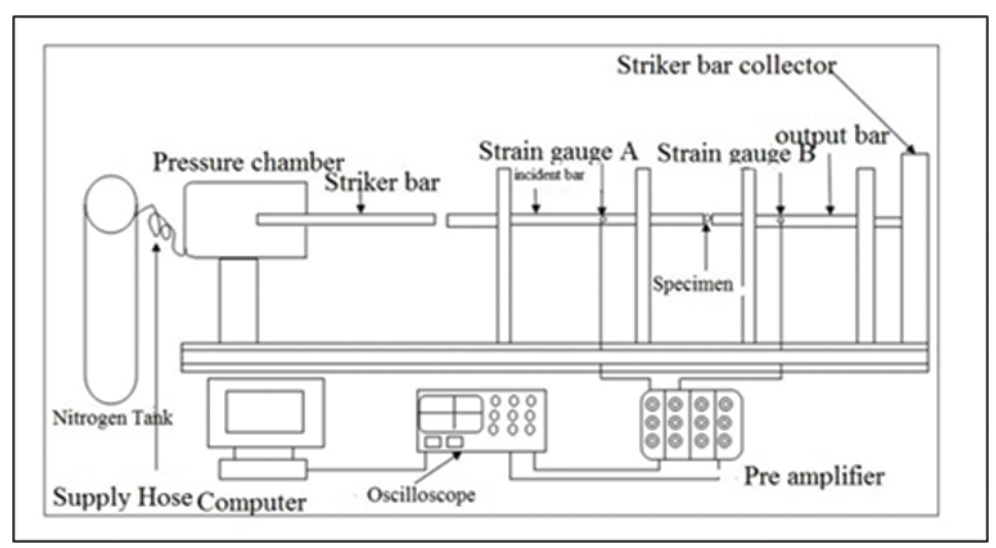

Fig. 1 Sketch of the split Hopkinson pressure bar system

rials is very critical to mechanical design for components subjected to explosive loading ${ }^{[10-12]}$, high speed machining ${ }^{[5,13]}$, metal forging, and ballistic or high velocity impact ${ }^{[14]}$.

The types of the adiabatic shear bands developed in an alloy at high strain rates depend on the composition, the heat treatment condition, and the severity of loading. For example an oil quenched high strength low alloy steel tempered at $600{ }^{\circ} \mathrm{C}$ may form the deformed bands under high velocity impact while the same steel form the transformed bands under similar loading condition when tempered at 300 or $400{ }^{\circ} \mathrm{C}^{[1]}$. The transformed bands are also called white etching bands because of their white color when viewed under an optical microscope after etching with Nital. As a result of their extremely fine microstructure, the material in the transformed bands are known to be much harder and more brittle than that outside of the band. Observations by TEM indicate that the microstructure consists of very fine grains of sub-micron size in the transformed adiabatic shear bands ${ }^{[14]}$.

The prevalent models for explaining the occurrence of shear bands in metallic alloys include the Zerilli and Armstrong model ${ }^{[20]}$, the Johnson Cook model ${ }^{[21]}$, and the Clifton model ${ }^{[22]}$. The Zerilli and Armstrong model is a dislocation pile up model where the blocking of dislocation on a slip plane by obstacles leads to extensive strain causing the formation of bands. This model uses dislocation mechanics concept to develop flow stress method in accounting for strain rate, strain, and temperature during dynamic impact loading. The Johnson Cook model is based on fracture strain criteria and it is a well-accepted numerical model for simulating stress-strain response under dynamic loading. According to this model, the slope of the flow stress curve is independently affected by strain hardening, strain rate sensitivity and thermal softening behavior.

In this paper, the Johnson Cook model is used to simulate the formation of adiabatic shear bands in AISI 4340 steel under impact loading. The effect of microstructural defect and impact velocity on the for- mation of adiabatic shear bands in AISI 4340 is also examined and simulated.

\section{Material and Experimental Method}

The AISI 4340 alloy steel investigated in this study contains 0.40 wt.\% $\mathrm{C}$ and varying amount of alloying additions which includes manganese, chromium, nickel, and molybdenum.

Cylindrical specimens with a diameter of $9.5 \mathrm{~mm}$ and $10.5 \mathrm{~mm}$ long were used for the impact tests. The test specimens were austenitized at $850{ }^{\circ} \mathrm{C}$ for $30 \mathrm{~min}$, oil quenched, and tempered at $315{ }^{\circ} \mathrm{C}$ for $60 \mathrm{~min}$. The heat-treated specimens were subjected to dynamic impact loading using the split Hopkinson pressure bar (SHPB) shown schematically in Fig. 1. The striker bar strikes the incident bar at a predetermined impact velocity, generating elastic waves which travel through the specimen to the transmitter bar. The incident, the reflected, and the transmitted elastic wave signals were captured by strain gages attached to the incident and the transmitter bars. The captured waves were amplified and recorded using a 4 channel digital oscilloscope. The captured elastic wave data in volt are converted to load value using the conversion factor obtained from an initial calibration of the equipment. The calibration process is explained in details elsewhere ${ }^{[23]}$. The deformed specimens were subjected to metallographic preparation using $0.2 \%$ Nital as the etching reagent and observed under optical and scanning electron microscopes.

\section{Constitutive Model}

Adiabatic shear bands are formed as a result of localized plastic deformation that occurs mostly at high strain rates. Thus, for adequate modeling of the deformation process and the formation of adiabatic shear bands, a rate-dependent constitutive model must be used $^{[5]}$. The Johnson Cook model ${ }^{[21]}$ relates the three mechanisms that are responsible for the development of adiabatic shear bands in materials experiencing 
dynamic shock loading: work hardening, strain-rate hardening, and thermal softening. The main advantage of this model is that it is relatively easy to calibrate with minimum experimental data in the form of stress-strain curves at different strain rates and temperatures $^{[24]}$. The Johnson Cook model assumes that the slope of the flow stress curve is independently affected by the strain hardening, the strain rate sensitivity, and the thermal softening behaviors. This model is given as:

$$
\begin{gathered}
\sigma_{\mathrm{eq}}=\left[A+B \varepsilon_{\mathrm{P}}^{n}\right]\left[1+C \ln \left(\frac{\dot{\varepsilon}_{\mathrm{P}}}{\dot{\varepsilon}_{\mathrm{po}}}\right)\right]\left[1-\left(T^{*}\right)^{m}\right] \\
T^{*}=\frac{T-T_{\text {room }}}{T_{\text {melt }}}-T_{\text {room }}
\end{gathered}
$$

where $\sigma_{\text {eq }}$ is the equivalent flow stress, $T^{*}$ is the homologous temperature, $T_{\text {melt }}$ is the melting temperature of the material, and $T_{\text {room }}$ is the room temperature. The equivalent plastic strain is represented by $\varepsilon_{\mathrm{P}}$, strain rate by $\dot{\varepsilon}_{\mathrm{P}}$ and the user defined reference accumulative plastic strain rate as $\dot{\varepsilon}_{\text {po }}$. The constant parameter terms $A, B, C, n$ and $m$ are fitted to the data obtained by several tests conducted at low strains and strain rates and at room temperature in a split Hopkinson pressure bar test ${ }^{[25]}$. Table 1 indicates the parameters used in Johnson Cook for the AISI 4340 steel which were utilized during the simulation process.

Table 1 Parameters used in Johnson Cook model ${ }^{[26]}$

\begin{tabular}{cc}
\hline Parameter & Value \\
\hline$A$ & $792 \mathrm{MPa}$ \\
$B$ & $510 \mathrm{MPa}$ \\
$C$ & 0.014 \\
$n$ & 0.26 \\
$m$ & 1.03
\end{tabular}

\section{Finite Element Modeling and Simulation}

The Johnson Cook constitutive model described in Section 3 is utilized in ABAQUS 6.10 finite element software to model the formation of adiabatic shear bands in the AISI 4340 steel. The cylindrical steel specimen is subjected to compressive force at high strain rates using impact loads. In order to model the initiation and growth of adiabatic shear bands, the cylindrical specimen was divided into three different sections, i.e. I, II and III as shown in Fig. 2. Due to symmetry, only half of the cylindrical specimen was modeled to render the simulations less computationally intensive. Section II is the region where the probability of strain localization is high based on prior experimental observation. The initial size of section II is $95 \mu \mathrm{m}$, which is $1 \%$ of the diameter of the cylindrical specimen. The initial yield strength

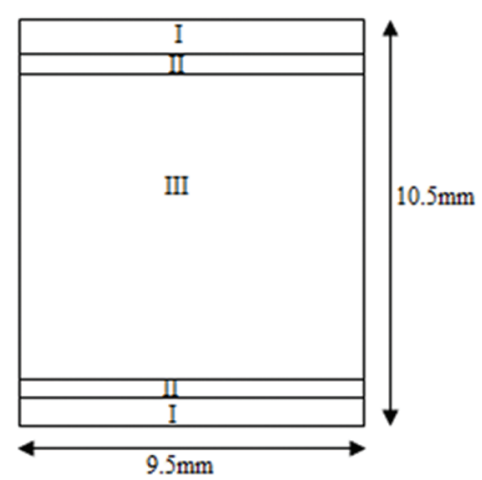

Fig. 2 Schematic representation of AISI 4340 model

$(A)$ and the initial strain hardening factor $(B)$ for section II were $60 \%$ of the values defined for sections I and III similar to the approach used in Ref. [2] for the same steel material subjected to torsion loads. This is based on the fact that material flaws such as microstructural defects referred to as initial perturbations are known to trigger the initiation of shear bands in materials subjected to dynamic impact and shock loads. Previous parametric studies have shown that the total effective perturbation in a tested specimen can be obtained by summing the initial perturbation in strength, temperature, and wall thickness ${ }^{[27]}$. Furthermore, the critical strain corresponding to the point of stress collapse is a logarithmic function of the size of the initial perturbation ${ }^{[28]}$. As the size of initial perturbation increases, the critical strain for stress collapse decreases logarithmically. Also previous work ${ }^{[29]}$ shows that differences in properties and microstructure cause adiabatic shear bands to form in the material.

A 3-dimensional modeling space of deformable type with solid extrusion base feature was used in constructing the model in the ABAQUS CAE. The material properties corresponding to the different sections making up the cylindrical specimen are stated in Table 2. Impact load was initially applied in the form of a projectile weighing $1.905 \mathrm{~kg}$ and moving at a velocity of $17 \mathrm{~m} / \mathrm{s}$. The simulation was performed using ABAQUS explicit solver based on the dynamic form of the compressive load. The explicit dynamics procedure performs a large number of small time increment iterations efficiently and hence suitable for the simulation. A stress-free state was defined as the initial condition since the deformation is to be accounted for from the initial point of impact and dynamic explicit step was utilized during the simulation. The bottom cross section of the model was fixed such that there

Table 2 Parameters of Johnson Cook model utilized in simulation for different sections shown in Fig. 2

\begin{tabular}{cccccc}
\hline Section & $A(\mathrm{MPa})$ & $B(\mathrm{MPa})$ & $C$ & $n$ & $m$ \\
\hline I and III & 792 & 510 & 0.014 & 0.26 & 1.03 \\
II & 475.2 & 306 & 0.014 & 0.26 & 1.03 \\
\hline
\end{tabular}




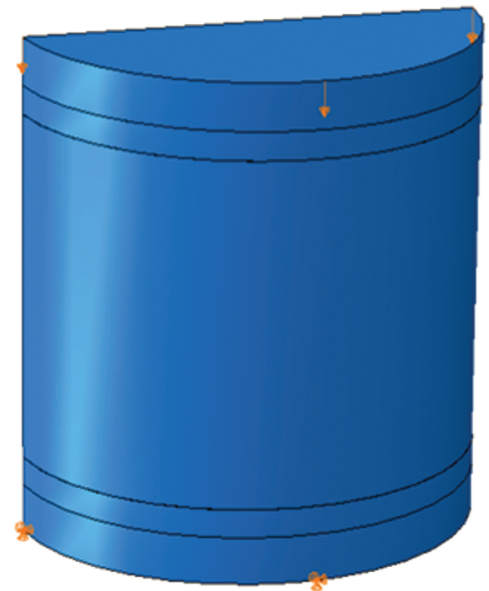

Fig. 3 3D model of cylindrical specimen showing boundary conditions and applied load

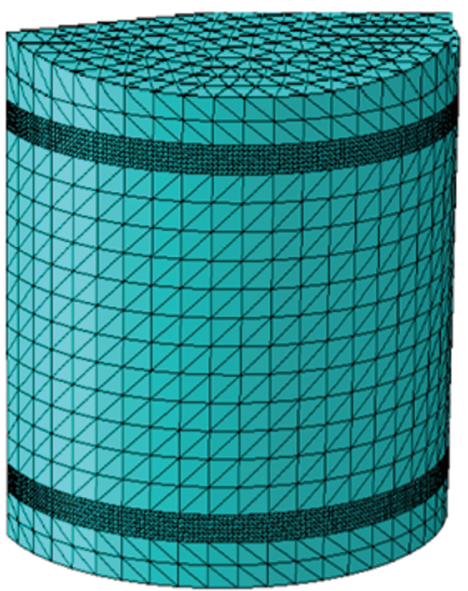

Fig. 4 Mesh discretization of AISI 4340 steel sample

exist no displacement in any directions at the bottom cross-section. The boundary conditions utilized during simulation are as follows: Sections I and III were discretized using a global seed size of 0.6 while section II was discretized using a global seed size of 0.1 . The difference in the discretization of the parts is based on the fact that understanding of strain localization in section II is of great importance in this study. The 4 node linear tetrahedron element type of $3 \mathrm{D}$ stress family was utilized in the discretization of the cylindrical specimen.

Fig. 4 shows the mesh discretization of the cylindrical steel specimen in ABAQUS environment based on the global seed size described.

\section{Results and Discussion}

The simulation results show strain localization in the section II of the specimen, this localized strain indicates that the adiabatic shear band is more likely to initiate in section II. This observation can be justified based on the fact that lower yield strength was declared for section II. The result of this simulation shows that material defect such as impurity or inho- mogeneity could contribute to the growth of an adiabatic shear band in a specimen under compressive load. This observation further confirms previous results in literature showing the effect of material inhomogeneity on the failure of materials under dynamic loads $^{[2]}$. For the simulation performed at an impact velocity of $17 \mathrm{~m} / \mathrm{s}$, it was observed that the maximum flow stress in the sample localized in section II is $1563 \mathrm{MPa}$ (see Fig. 5(a)). The path of maximum flow stress of $1563 \mathrm{MPa}$ has a thickness of about 600 $\mu \mathrm{m}$ and is the region where the probability for formation of adiabatic shear band is highest. Experimental result in Fig. 5(a) shows that the maximum flow stress which is experienced in the specimen when it is impacted at a velocity of $17 \mathrm{~m} / \mathrm{s}$ was $1620 \mathrm{MPa}$. The deviation of the simulation results from the experimental result is $3.64 \%$. Considering the influence of dispersion of shear waves in the split Hopkinson pressure bar and slip effect during experiment, the difference between the maximum flow stresses obtained from the simulation and experimental results can be justified. The small differences between the simulation and experiment results may also be attributed to microstructural and metallurgical and/or surface imperfections that cannot be accounted in the model implemented.

The influence of the impact velocity on the initiation and growth of the shear bands was also studied in this work. Fig. 5(b) shows the result obtained for both the simulation and experimental tests performed at a velocity of $19 \mathrm{~m} / \mathrm{s}$. For the simulation, the constitutive model parameters, used at the velocity of $19 \mathrm{~m} / \mathrm{s}$, were the same as those used at the velocity of $17 \mathrm{~m} / \mathrm{s}$. From Fig. 5(b), the maximum flow stress experienced by the sample is $1659 \mathrm{MPa}$ for the simulation results at the impact velocity of $19 \mathrm{~m} / \mathrm{s}$. A maximum flow stress of $1709 \mathrm{MPa}$ was observed during the experiment performed at the same impact. The deviation of the simulation results from the experimental result being about $3.01 \%$. A maximum flow stress of about $1773 \mathrm{MPa}$ was observed for the simulation performed at an impact velocity of $21 \mathrm{~m} / \mathrm{s}$ (see Fig. 5(c)). The maximum flow stress observed within the steel during the testing at the same velocity of $21 \mathrm{~m} / \mathrm{s}$ was $1821 \mathrm{MPa}$. This means that there exists a $2.7 \%$ deviation between the simulation and experimental results. From Fig. 5, it can be seen that at the onset of the stress versus the strain curves, strain hardening dominates the plastic deformation until a maximum flow stress is reached. After the maximum flow stress, thermal softening dominates the deformation process. The rapid stress collapse as a result of mechanical instability is due to intense adiabatic heating along the narrow path that leads to the strain localization. The strain corresponding to this stress collapse is the critical strain for the occurrence of the adiabatic shear bands. Fig. 5 also shows that as the impact velocity increases, the critical strain at which the thermomechanical instability occurs also increases. The 

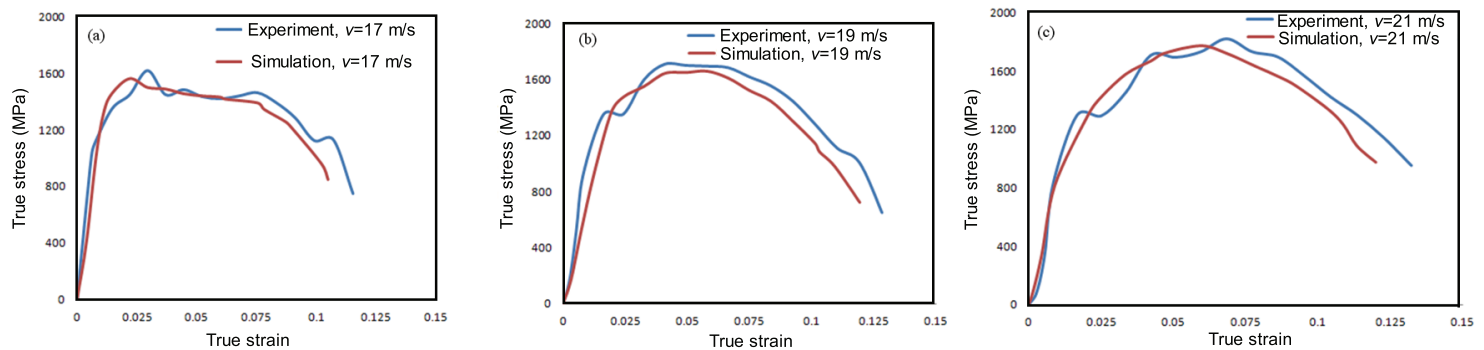

Fig. 5 Experimental and numerical stress vs. strain curves obtained during loading of AISI 4340 steel at various velocities: (a) $v=17 \mathrm{~m} / \mathrm{s}$; (b) $v=19 \mathrm{~m} / \mathrm{s}$; (c) $v=21 \mathrm{~m} / \mathrm{s}$
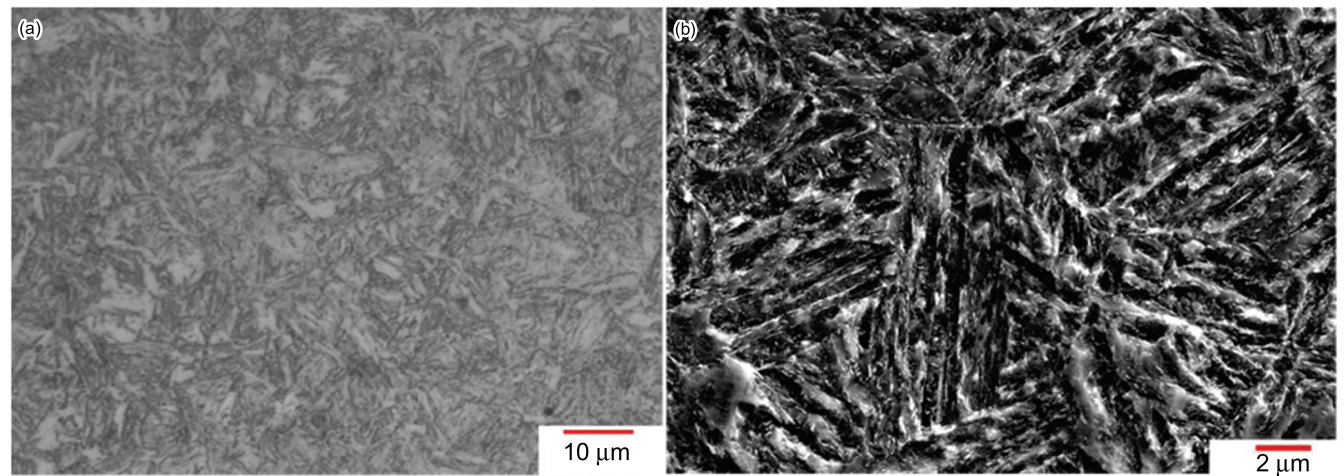

Fig. 6 OM (a) and SEM (b) micrographs of AISI 4340 specimens before impact test

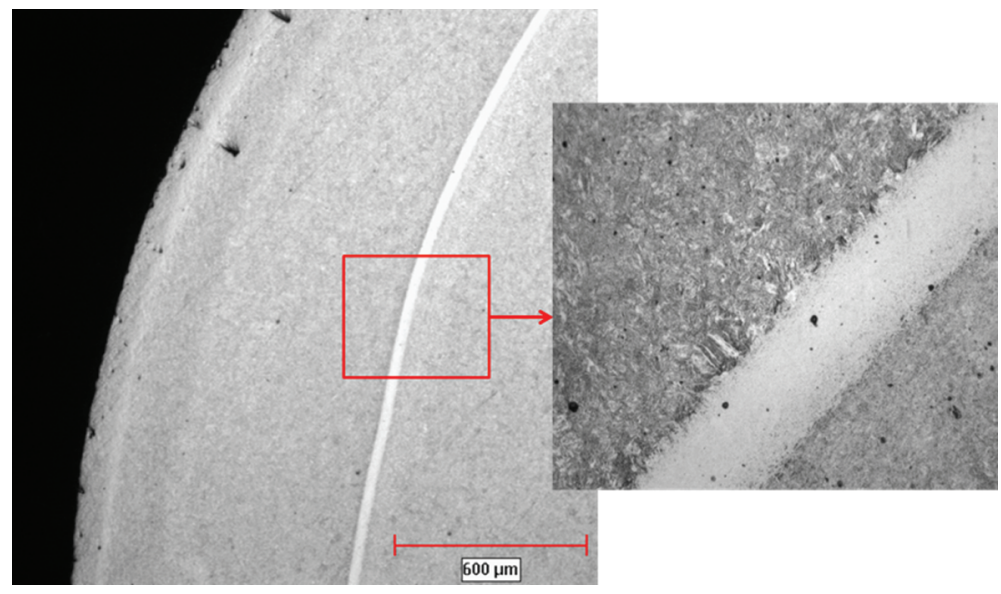

Fig. 7 Optical micrographs of cylindrical specimen of AISI 4340 steel impacted at $17 \mathrm{~m} / \mathrm{s}$

increase in the critical strain for instability is due to increasing thermal softening and plastic strain in the specimen as impact momentum increases. It has also been observed that as the impact velocity or strain rate increases, the maximum flow stress increases. Lee and $\operatorname{Lin}^{[30]}$ also suggested that as the strain rate increases, the stress increases at any specific strain.

Fig. 6 shows the optical and scanning electron micrographs of the original AISI 4340 steel after the heat treatment procedure before the impact test. The microstructure of the quench-hardened and tempered specimens consists of the martensite plates and the retained austenite. The white areas in the microstructure represent the retained austenite, the untrans- formed austenite after quenching in oil.

The optical micrographs showing a fully developed transformed band observed on the transverse section of the specimen impacted at $17 \mathrm{~m} / \mathrm{s}$ are presented in Fig. 7. The band propagated along a circular path close to the circumference of the circular cross section of the specimen. The microscopic features of the transformed bands could not be resolved under the optical microscope. There have been a number of explanations for the white color of the transformed bands. It has been suggested to be etching effect on the material constituting the transformed bands ${ }^{[31]}$. Zurek $^{[32]}$ attributed the white color to resolution limit of optical microscopy in resolving the nanosized grains 

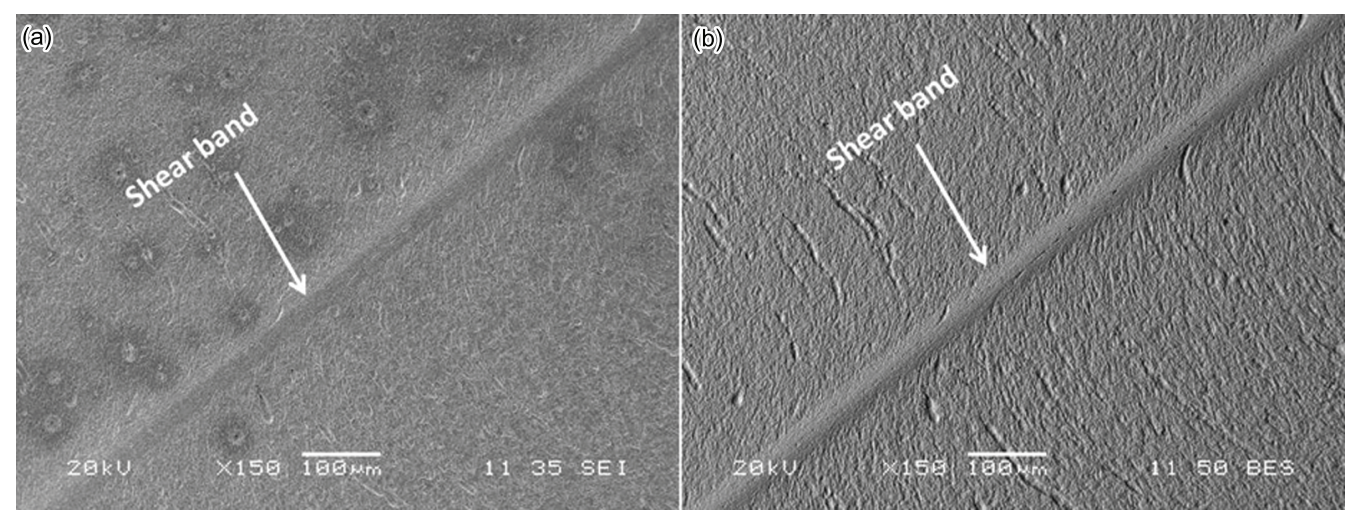

Fig. 8 SEM images showing a transformed band in impacted AISI 4340 steel: (a) secondary electron image; (b) back-scattered electron image

inside the transformed band in steels.

The scanning electron microscopic micrographs obtained from secondary and back-scattered electrons at low resolution (X150) are presented in Fig. 8. While the transformed bands on the secondary electron image is on the same plane as the rest of the materials. There appear to be protrusions along the shear bands in the back-scattered electron image. A protrusion along transform band in the sample might be an indication that the transformed bands are more difficult to etch than the rest of the material. There is however a need to investigate the topography of the surface of the specimen using an atomic force microscope to provide additional validation to this observation.

The investigated quench-hardened and tempered (at $315{ }^{\circ} \mathrm{C}$ ) AISI 4340 specimens showed high susceptibility to strain localization and the occurrence of transformed shear bands under impact loading. This can be attributed to its low strain hardening coefficient. The carbide forming alloying elements in the steel such as molybdenum and chromium will generate carbides that can introduce perturbations in the microstructure which can promote the nucleation and growth of adiabatic shear bands. The formation of transformed bands in pearlitic steel has been explained using dynamic recovery mechanism ${ }^{[17]}$. This involves grain elongation, re-orientation along shear stress flow direction and fragmentation. The final stage of the recovery process involves spheroidization which results into a band having densely packed fine subgrains.

The formation of ultra-fine grains inside transformed bands in metallic alloys have been attributed to the formation of new grains as a result of combine action of adiabatic heating and intense strain localization inside the shear bands. As a result of the very small deformation time, static recrystallization by grain boundary migration, which involves atomic diffusion, cannot adequately explain recrystallization in the transformed bands. Dynamic recrystallization mechanism has been proposed to explain the

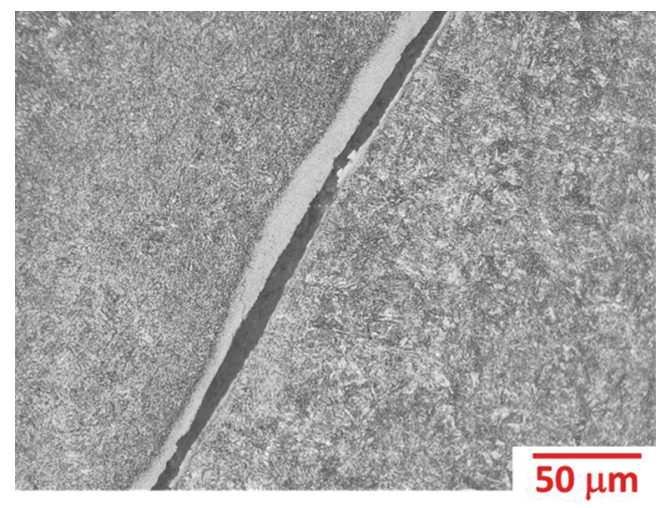

Fig. 9 Optical micrograph showing cracks along a white etching band for martensitic AISI 4340 specimen impacted at $19 \mathrm{~m} / \mathrm{s}$

formation of new recrystallized grains in the transformed bands ${ }^{[3]}$. This has been reported to involve grain boundary rotation rather than grain boundary migration ${ }^{[18]}$. It is suggested to occur in the following steps: (a) dislocation multiplication; (b) their patterning into elongated cells; (c) break down of the dislocation cells into sub-grains by accumulation of dislocation at the subgrain boundaries and finally; (d) reorientation or rotation of the subgrains boundaries to form equi-axed cells ${ }^{[19,33]}$. Grain boundaries have been attributed to be the source of the dislocation multiplication that initiates the dynamic recrystallization in the transformed bands.

The transformed bands serve as the crack initiation and propagation path as shown in Fig. 9 for the specimen impacted at the velocity of $19 \mathrm{~m} / \mathrm{s}$. Thus damage evolution in the steel under the impact loading begins with shear strain localization leading to formation of transformed bands. Both ductile shear and knobbly failure mode have been reported on the fracture surface for this steel in the region, where crack propagated along transformed bands ${ }^{[1]}$. Typical fragmented specimens showing conical shape of the shear bands are presented in Fig. 10. 


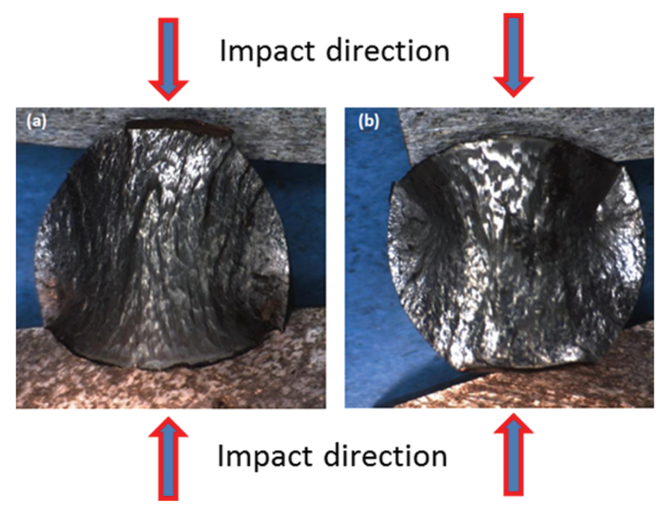

Fig. 10 Optical macrographs of fractured cylindrical specimen of martensitic AISI 4340 specimen

\section{Conclusion}

Experiment tests were conducted on cylindrical specimens to determine the initiation and growth of adiabatic shear bands in steel AISI 4340 steel that undergo dynamic impact loads. Finite element simulation of the cylindrical specimens was performed using ABAQUS 6.10. Results show that the region of lower yield strength and strain hardening factor experienced more strain localization and hence higher possibility of failure. Simulation was also performed at different strain rates in order to determine the influence of varying impact velocity on the growth of adiabatic shear bands. The results show that an increase in impact velocity results in the alloy experiencing more work hardening before thermal softening begins to dominate the deformation process. This in turn results into an increase in the maximum strain localization within the material and hence higher possibility for the initiation and the growth of adiabatic shear bands. Cracks were initiated and propagated along transformed bands leading to fragmentation under the impact load. The susceptibility of the adiabatic shear bands to cracking is markedly influenced by strain rates.

\section{Acknowledgements}

The authors are grateful for the support provided by the Department of Defense (DoD) through the research and educational program for HBCU/MI (contract No. W911NF-12-1-061) monitored by Dr. Larry Russell (Program Manager, ARO).

\section{REFERENCES}

[1] A.G. Odeshi and M.N. Bassim, Mater. Sci. Eng. A $\mathbf{5 2 5}$ (2009) 96.

[2] H. Feng and M.N. Bassim, Mater. Sci. Eng. A 266 (1999) 255.

[3] S. Kuriyama and M.A. Meyers, Metall. Trans. A 17
(1986) 443.

[4] A.G. Odeshi, M.N. Bassim and S. Al-Ameeri, Mater. Sci. Eng. A 419 (2006) 69.

[5] T.C. Lee, L.C. Chan and B.J. Wu, J. Mater. Process. Technol. 48 (1995) 105.

[6] V.F. Nesterenko, M.A. Meyers and H.C. Chen, Acta Mater. 44 (1996) 52017.

[7] C.J. Shih, M.A. Meyers and V.F. Nesterenko, Acta Mater. 46 (1998) 4037.

[8] K. Ravi-chandar, J. Lu, B. Yang and Z. Zhu, Int. J. Fract. 101 (2000) 33.

[9] M.N. Bassim and A.G. Odeshi, Mater. Sci. Eng. 31 (2008) 69.

[10] S.E. Schoenfeld and T.W. Wright, Int. J. Solids Struct. 40 (2003) 3021.

[11] K.M. Cho, S. Lee, S.R. Nutt and J. Duffy, Acta Metall. Mater. 41 (1993) 923.

[12] Q. Xue and G.T. Gray, Metall. Mater. Trans. A 37 (2006) 2447.

[13] K.C. Dao and D.A. Schockey, J. Appl. Phys. 50 (1979) 8244.

[14] M.A. Meyers and C.L. Wittman, Metall. Trans. A 21 (1990) 3153.

[15] L. Zener and J. H. Hollomon, J. Appl. Phys. 15 (1944) 22.

[16] J. Barry and G. Byrne, Mater. Sci. Eng. A 325 (2002) 356.

[17] Z.H. Chen, L.C. Chan, T.C. Lee and C.Y. Tang, J. Mater. Process. Technol. 138 (2003) 610.

[18] M.A. Meyers, Y.J. Chen, F.D.S. Marquis and D.S. Kim, Metall. Trans. A 26 (1995) 2493.

[19] J.F.C. Lins, H.R.Z. Sandim, H.J. Kestenbach, D. Raabe and K.S. Veechio, Mater. Sci. Eng. A 457 (2007) 205.

[20] R.W. Armstrong and F.J. Zerilli, Mech. Mater. 17 (1994) 319.

[21] G.R Johnson and W.H. Cook, Proceedings of the 7th International Symposium on Ballistics, Hague, Netherlands, 1983, pp.541-547.

[22] R.J. Clifton, J. Duffy, K.A. Hartley and T.G. Shawki, Scr. Metall. 18 (1984) 443.

[23] G.T. Gray, ASM handbook 8 (2000) 462.

[24] F.H. Abed, Ph.D. thesis, Louisiana State University and Agricultural and Mechanical College, Louisiana, U.S., 2005.

[25] T. Ozel and Y. Karpat, Mater. Manuf. Process. 22 (2007) 659.

[26] T. Ozel and F. Pfefferkon, ASME International Conference on Manufacturing Science and Engineering, Atlanta, GA, U.S., October 15-18, 2007.

[27] T.W. Wright, J. Mech. Phys. Solids 38 (1990) 515.

[28] A. Molinari and R.J. Clifton, J. Appl. Mech. 54 (1987) 806.

[29] M.N. Bassim, J. Mater. Process. Technol. 119 (2001) 234.

[30] W.S. Lee and C.F. Lin, Mater. Sci. Eng. A 308 (2001) 124

[31] C.L. Wittman M.A. Meyers and H.R. Pak, Metall. Trans. A 21 (1990) 707.

[32] A.K. Zurek, Metall. Trans. A 25 (1994) 2483.

[33] Y. Xu, J. Zhang, Y. Bai and M.A. Meyers, Metall. Mater. Trans. A 39 (2008). 